\begin{tabular}{|c|c|c|}
\hline $\begin{array}{l}\mid N F Q B A I N \\
P \cup B L I C A T I O N\end{array}$ & $\begin{array}{l}\text { International Journal of Advanced Engineering, Management and Science } \\
\text { (IJAEMS) } \\
\text { ISSN: } 2454-1311 \\
\text { Vol-7, Issue-1; Jan, } 2021 \\
\text { Journal Home Page Available: } \underline{\text { https://ijaems.com/ }} \\
\text { Journal DOI: } \text { https://dx.doi.org/10.22161/ijaems } \\
\text { Article DOI: } \text { https://dx.doi.org/10.22161/ijaems.71.11 }\end{array}$ & 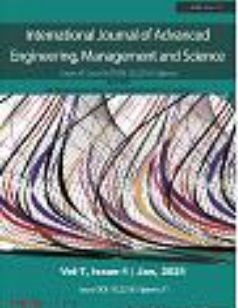 \\
\hline
\end{tabular}

\title{
Incest the victims and their abusers
}

\author{
Ma. Florisa T. Quiajno ${ }^{1}$, Merlina C. Garcia ${ }^{2}$, Gerald A. Quijano ${ }^{3}$, Lyka Mae L. Fajardo ${ }^{4}$
}

${ }^{1,3}$ Fort Magsaysay Campus, Nueva Ecija University of Science and Technology, Philippines
${ }^{2,4}$ Atate Campus, Nueva Ecija University of Science and Technology, Philippines

Received: 17 Nov 2020; Received in revised form: 05 Jan 2021; Accepted: 19 Jan 2021; Available online: 31 Jan 2021 C2021 The Author(s). Published by Infogain Publication. This is an open access article under the CC BY license (https://creativecommons.org/licenses/by/4.0/).

\begin{abstract}
The goal of this study, Incest The Victims and Their Perpetrators, was to determine the incidence of victims of incest in Nueva Ecija Home for Girls. Incest is described as a child's sexual exploitation by a parent or other entity that has control over the child. Violence can occur in various degrees of age, locations, and forms. Victims experience mental depression, not only do the results of abuse end up in the latter, but it also has a psychological effect on both victims and families. Incest is characterized as a child's sexual exploitation by a parent or other entity with authority over the child. Stories of violence and sexual assault are frequently seen on television, but few are concerned and aware of the potential support they can give to victims, so victims cannot speak out on their own because they know it and see it as a very humiliating and tragic event.

Careful consideration was given to the profile of both victims and perpetrators in terms of demographic, economic and educational variables. During therapy sessions involving counseling, evaluation and in-depth examination of the case of molested individuals at the Palayan City Girls Home, Nueva Ecija, the researchers would like to examine the impacts of abuse. The researchers would also like to know the causes of this exploitative activity to determine the level of awareness of the community with regards to the abused, especially in women of young age who do not have enough wisdom to defend themselves. Concern of this research focused also on the status of social and psychological support.

The researchers used interview and observation method of gathering information for the cases.The findings of this study shows that sexual exploitation is common and victims belong to low class families. The abused are psychologically disturbed and its impact last for many years.

The study revealed that there were also NGOs and GOs which were ready to help and support the victims. Perpetrators of incest were seldom jailed. The justice system is to slow to respond to the cases of sexual violence. The children with stepfathers and working mom had greater possibilities of having abused children. Incest cuts across all ethnic religious groups in our society. Incest also shows that children in the Philippines were obedient to parents and were willing to sacrifice themselves than to voice out their secrets. Victims have feelings of isolation and mistrust.
\end{abstract}

Keywords_incest, victims, abusers, violence, perpetrators.

\section{INTRODUCTION}

Around the world, violence against women occurs in different forms and degrees. Philippines is no exception. Violence not only harms women physically, it also leaves deep psychological impact on both the victims and their families. Even their communities and the nation as a whole are affected by violence against women.

Incest which is defined as "the sexual abuse of a child by relative or other person in a position of trust and authority over the child" does not discriminate. It can happen in families that are financially-privileged, as well as those of 
low socioeconomic status. It can happen to those of all racial and ethnic descent, and to those of all religious traditions. Victims of incest are boys and girls, infants and adolescents. Incest occurs between fathers and daughters, fathers and sons. Perpetrators of incest can be aunts, uncles, cousins, nieces, nephew, step-parents, stepchildren, grandparents and grandchildren. In addition, incest offenders can be person without a direct blood or legal relationship to the victim such as a parent's lover or live-in nanny, housekeeper, etc. - as this abuse takes place within the confines of the family and the home environment. It is a violation of the child where he or she lives - literally and metaphorically. A child molested by a stranger can run home for help and comfort. A victim of incest cannot.

Incest cases are increasingly reported in the Philippines. Data from the Department of Social Work and Development (DSWD) reveals the prevalence of incest nationwide. From 2001 to 2013, the number reported incest cases reached 5.678 from 1,908 in 1991. For 2013 alone, the DSWD document 2,789 cases of incest out of the 4,789 reported cases of sexual abuse of children. The top five regions with the most number of reported incest cases are the National Capital Region with 1787 cases, followed by Region IV (987 cases), Region III (589 cases), Region VII (345 cases), and Region V (198 cases).

Available data cover only reported case and is mostly quantitative. Little is known about the profile incest victim, their abusers and the circumstances behind incest.

This study was conducted in order to have an in depth understanding of incestuous activity. Specifically, this study tried to:

1. To analyze the victim and abuser's profile in terms of demographic, economics and educational variables.

2. To analyze the psychological impacts of violence, especially on the lives of the victims as they were still undergoing therapy in the Home for Girls.

3. To analyze the social and physical impacts of sexual violence on the lives of the victims.

4. To determine the causes of this exploitative activities.

5. To determine the status of community awareness to sexual abuses especially on women of young age.

6. To determine the status of social and psychological support being provided for victims of sexual violence.

7. To provide directions for policy and programs formulation for minimizing and redressing sexual violence by all concerned social and legal sectors.

\section{METHODOLOGY}

The study used the descriptive research in so far as the existing condition of the sample population is concerned. Data were gathered through survey questionnaires. Guided interviews and observations were also employed

The researchers interviewed 6 victims of incest; all are under the custody of the Department of Social Workers and Development, Home for Girls in Palayan City. Its main function is to provide the basic needs such as shelter, food and education of girls and women of young age who are in one way or another became the victim of child and women abuses. They also give physical, social and psychological therapy to the victims.

\section{RESULTS AND DISCUSSION}

\subsection{Demographic Variables ( Victims )}

\subsubsection{Age}

Victims were of 8-17 years of age. Children and mid-teens were the usual victims of sexual violence.

\subsubsection{Ethnicity}

Three (3) of the six (6) victims were Tagalog, two (2) were Ilocanos and one from Visayas. Two (2) victims were Iglesia ni Cristo and the remaining four (4) were all Roman catholic.

\section{Demographic Variables (Abusers)}

\subsubsection{Age}

The age of abusers ranged from 40 to 70 years of age. There were also adolescents' abusers.

\subsubsection{Ethnicity}

Some abusers were Tagalog, some were Ilocanos and others from the Visayas Region. Iglesia ni Cristo and Roman Catholic were the abuser's religion.

\subsection{Economic Variables (Victims)}

\subsubsection{Economic Status}

Two (2) of the victims were children of farmers and four (4) belonged to wage laboring families

\subsubsection{Education}

Two (2) victims were educated up to the secondary level. Another two (2) were in the college level and the remaining two (2) were in the elementary level.

\subsubsection{Place of Residence}

Some victims were living with their parents, some with step or foster parents and some with grandparents and one with friends before the incident. After the incidents they were all brought to Home for Girls in Palayan City. This 
institution served as their shelter while they were undergoing psycho-social therapy.

\section{Economics Variables (Abusers)}

\subsubsection{Economic Status}

Some of the abusers were farmers and some were laborers. Other abusers were jobless.

\subsubsection{Education}

Most of the abusers attained a secondary education. No one earned a college diploma or even stepped in the college level.

\subsection{About the Incident}

\subsubsection{Identity of Perpetrator}

These shocking interviews have revealed the identity of the perpetrator to be the father, grandfather, brother and stepfather. Most of the victims had known the perpetrators from their early childhood and have trusted them implicitly and seen no reason to doubt their behaviors. Some abusers were introduced to the victims after their mother marriages and learned to regard and trust them according to the legal relationship that has existed.

\subsubsection{Time}

Most exploitative incident or relationships took place more than three (3) to four (4) years ago. Some incidents took place a year ago. It was mostly at day time when the mother was in her work and some at night time.

\subsubsection{Venue of Incident}

All the exploitative incidents occurred in the home of the victim and perpetrator.

\subsubsection{Duration of Relationship}

Most of the cases were not just a one-time incident but longer-term abuses.

\subsection{Willing or Forced Partner's in Crime}

While most of the victims were forced to engage in an incest activity. There were two victims who said they were willing victims but they did not understand how it happened.

\subsection{Silence and Sharing of the Incident}

In the majority of cases the victims had initially kept quiet about the incident due to a number of complex reasons, including mostly because of fear of social stigma, and shame and fear of the perpetrator. Some of them did not share the incident with anybody because they were threatened into silence. Some of them also mentioned guilt as a reason for keeping silent; as they believed that they were also part of the relationship.

When they finally chose to share the incident most of them reported sharing it with their mothers while others kept quiet for weeks, months and years and finally shared it with person outside their home. They shared it with neighbors, counselors and to social workers.

\subsection{Impacts of Incest}

\subsubsection{Psychological Impacts}

In the case of incest, more than any form of sexual violence, the victim feels a lot of guilt of having participated, willingly or forcibly, in a sexual relationship with a blood or close relative. The victim or even the willing victim reluctantly harbors a lot of very negative feelings about themselves. Some of these feelings were reported by the respondents as being under stressed most of the time and feeling scared. A number of them felt guilty and blamed them for the incestuous relationship and also suffered sleep disturbances. The majority of them also hated themselves, had frequent mood swings and felt angry. Others also expressed wanting to crust often and not wanting to talk to anybody and being upset very easily. They were plagued by feelings of helplessness and did not respect themselves and even wanted to commit suicide. Some also mentioned they do not want to get marry or even have a normal emotional relationship with anybody. Some also said they could not do anything positive in their lives and would amount to nothing.

\subsubsection{Physical Impacts}

Physically the incident had negatively affected the respondents to the extent that most of them hated their bodies and even tried to hurt themselves and some tried to dress unattractively all the time.

\subsubsection{Social Impacts}

Due to the incidents the victims also felt socially disadvantaged and complexed. Majority of them felt that their family members blamed them as well as avoided them. Some of them hated going for the social functions, while others didn't even feel like talking to others. They were also plagued by feelings of being treated as social outcast, of others talking about them and blaming them for the incident. They also felt they would not be able to get married. A number of them were forced to leave their home or the community after the incident came out in the open.

\subsection{Feelings towards Perpetrator}

The negative feelings expressed towards the perpetrator were revulsion, numbness, anger, disgust, pain wanting to kill. These were all definitely feelings.

\subsection{Response of Family and Community}

Majority of the victims said that the community were angry with the perpetrator and shared their disapproval 
with the incident but most of their families were unproductive to them. Their families were angry with them and blamed them for the incident.

\subsection{Reaction of Friends}

The responses of the victims' friends were similar to the response of the community. They also showed anger to with the perpetrator. But there was also one victim who did not know what her friends thought of her.

\subsection{Law Enforcement}

Reporting personally to law agencies was found to be low as can be expected in crimes of this nature. Somebody told the law enforcement of what happened other than the victim herself.

\subsection{Social Support}

There were NGOs and GOs who were ready to give help to the victims of these cases.

\section{CONCLUSIONS}

4.1 Sexual exploitation of young girls and women is a chilling but now a common occurrence in the Philippine society. Most of the victims were barely out of their childhood.

4.2 Most victims were seen to belong to low-class families.

4.3 All victims of sexual violence were psychologically disturbed and lived under a lot of tension and stress. The negative impacts of sexual violence lasted for many years.

4.4. The cases only revealed that not at all times the family remained the strongest institution to provide help like most of us believed. Luckily there were NGOs and GOs which were ready to help and support victims of these cases.

4.5 In cases of incest action was taken by the family against the perpetrator however this action was not necessarily legal action.

4.6 Perpetrators of incest were seldom jailed.

4.7 The criminal justice system was slow to respond to cases of sexual violence.

4.8 The government system is yet to acknowledge the psychological needs of victims of sexual violence as an issue.

4.9 Violence against women in the form of incest undermines the function of the family. Particularly the family's role in providing shelter, protection and nurturing its members was threatened by violence inside the home.

4.10 Working mothers have a greater possibility of having abused children.
4.11 Children with stepfathers were more prone to exploitative activity such as incest.

4.12 Sexually molested women lost interest in education thus leading to economic lost to society in the long run.

4.13 Incest cut across all ethnic and religious groups in our society.

4.14 Incest showed that children of our society were obedient to parents and would avoid scandal in any way they could even to sacrifice themselves.

4.15 In our culture which placed great importance on female virginity (Equating it with purity, virtue and honor) the trauma of an abused girl is aggravated by a sense of worthlessness.

4.16 Female incest victims felt abandoned by their mothers and emotionally abandoned by both parents, and they developed negative images about themselves and their mothers. They also had interpersonal problems of feeling isolated and mistrust men.

4.17 What the victims felt to their perpetrator were feelings that no normal human being could live with every day of their lives. Given the young age of the victims could only be assumed that the normal and healthy overall chance for growth of these children had been negated by this one incident.

\section{RECOMMENDATION}

\subsection{Strategy for Awareness Creation}

This study clearly highlighted the need to create awareness about this form of violence against women. If parents, guardians and potential victims knew what the danger signs were many of them would not fall prey to incest.

The strategy for awareness creation would have to constitute of messages and programs suited to people at all levels and from all walks of life. Both traditional and mass media will have to be utilized to address audiences such as youth, especially young girls who are most victimized. Parents, guardians, teachers, politicians and policy makers also need to be sensitive gender discriminations and gender violence. This study strongly recommends an awareness program in school and campuses. There is a clear need for messages to be in different dialects and languages in order to reach a larger audience.

\subsection{Advocacy For Victims Support}

Besides creating awareness about this form of violence at the national level, it would be extremely important to sensitize and advocate at the policy level to provide support services for victims. Similarly, advocacy is 
required to address gaps in the law as well as to effectively enforce existing laws. Advocacy is also required to lobby with human rights groups and politicians to include this issue on their agenda. Advocacy will be required in the police force to enable more sensitive handling of cases.

\subsection{More Effective Law Enforcement}

The process of law enforcement needs to be improved is obvious. The Findings of this Study points towards the need to expand the services of the police in different districts of the country.

\subsection{Establishing Support Services}

The creation of more NGOs and GOs is needed to cater the different needs of the victims which they do not found in their respective families. Local government funds should be tapped to create support services.

\subsection{Mobilizing Communities and Networking to prevent Violence}

The study indicates the need to create sentinel systems to empower members of the community to prevent and deal with such cases of violence within the community. In this case again the community has proved to be an effective intermediary institution to deal with cases of violence against girls. To make these sentinel systems more effective a networking mechanism should be created. The network would be useful in expediting justice and in providing broader social support and acceptance to victims.

\subsection{Empowerment of Women and Girls}

A longer-term strategy is essential for the overall empowerment of girls and women. The need to develop self-esteem and confidence as well as economic independence forms the very basis of preventing the victimization of girls and women. Making education compulsory up to the high school level would allow girls to make choices about their lives. This ability to make choices would ultimately empower them and prevent their victimization. Thus, it is recommended that the government pursue the policy of free and compulsory education for all. It is also recommended that all development programs regardless of the sector they are operating in must compulsorily be required to conduct training on self-esteem, building leadership, human and legal rights training for women and girls as well as training on awareness building on the issue of violence against women and girls.

\subsection{Entry-Level Programs and Partnerships}

As it is not possible for total outsiders to enter any community and directly address such sensitive issue it is recommended that entry-level programs be initiated to build rapport and trust with local communities. The other strategy recommended is to establish partnership with groups already working in different communities.

\subsection{Gender Sensitization}

Messages to create a more equal society must also be delivered to mass media. School curricula should also address this crosscutting dimension of discrimination and address it from both the male and female points of view to initiate positive change.

\section{REFERENCES}

[1] Philippine Statistics Authority (PSA) and United Nations Children's Fund (UNICEF). Child Poverty in the Philippines. 2015

[2] Sanapo MS, Nakamura Y. Gender and Physical Punishment: The Filipino Children's experience. Child Abuse Review 20 (1). 39-56. (2011)

[3] Kandella Seema. Incestuous Rape and the Death Penalty in the Philippines: Psychological and Legal Implications. June 2006

[4] Ansara PL, Hindi MJ. Perpetration of intimate partner aggression by mom and women in the Philippines. Journal of Interpersonal Violence. 24 (9), 1579-1590. 2009

[5] Department of Social Welfare and Development. Voice from the Islands: Annual Report 2015

[6] Rape within the family: The Philippine's silent incent problem. (2017). Retrieved from https://www.rappler.com/newsbreak/investigative/incestrape-philippines-sexual-abuse

[7] Incestuous rape and death penalty in the Philippines: Psychological and legal implications. (June 2006). Retrieved from https://www.researchgate.net/publication/228144614_Incest uous_Rape_and_the_Death_Penalty_in_the_Philippines_ 